\title{
CT chest of COVID-19 patients: what should a radiologist know?
}

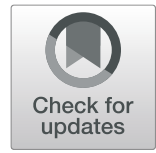

Tamer F. Ali ${ }^{*}$ (D), Mohamed A. Tawab ${ }^{2}$ and Mona A ElHariri ${ }^{1}$

\begin{abstract}
Background: The aim of current work is to review the CT findings of COVID-19 in a pictorial study to help the radiologists to be familiar to imaging findings of COVID-19.

Main body: Coronavirus disease 2019 (COVID-19) is a pandemic highly infectious disease which is first reported in December 2019 in Wuhan, China, and then had its outbreak leads to a global public health emergency. Real-time reverse transcription polymerase chain reaction (RT-PCR) of viral nucleic acid is considered as the reference standard for COVID-19 diagnosis; however, recent studies showed the importance of CT chest in the diagnosis of COVID-19 with high sensitivity.

The CT hallmarks of COVID-19 were bilateral peripheral ground-glass opacities, consolidation with the advance of the disease more consolidation is there with linear opacities and crazy-paving pattern as well as halo and reverse halo sign.

Conclusion: Early identification of COVID-19 cases is vital. The radiologist should be familiar with the possible findings. Further future studies with pathological correlation will help for more understanding of the imaging findings and its value in assessing of prognosis.
\end{abstract}

Keywords: COVID-19, GGO, CT chest, Pneumonia, Consolidation

\section{Background}

Coronavirus disease 2019 (COVID-19) is a pandemic highly infectious disease which is first reported in December 2019 in Wuhan, China, due to severe acute respiratory syndrome coronavirus 2 (SARS-CoV-2). On January 30, 2020, the World Health Organization (WHO) announced this outbreak as a global public health emergency and raised it to the very high risk on February 28, 2020 [1-7].

Understanding the clinical presentation of COVID-19 is of big importance; the clinical presentations are variable and can include fever as a major presentation; other symptoms include fatigue and cough, while some literature reported diarrhea and nausea to precede fever. Some cases can be asymptomatic, while elderly cases

\footnotetext{
*Correspondence: Drtamerfathi@yahoo.com

'Department of Radiodiagnosis, Faculty of Medicine, Zagazig University, PO. BOX 184, Sharkia, Zagazig 44511, Egypt

Full list of author information is available at the end of the article
}

with comorbidities are more vulnerable for respiratory failure. While patients may have normal or low WBCs, RBCs and platelet count with prolonged activated thromboplastin time and increased CRP [5-8].

Real-time reverse transcription polymerase chain reaction (RT-PCR) of viral nucleic acid is considered as the reference standard for COVID-19 diagnosis [8-11]; however, recent studies showed the importance of CT chest in the diagnosis of COVID-19 with high sensitivity [11-20].

According to the official diagnosis and treatment protocol (6th edition) issued by the National Health Commission of China [21], CT examination is of great help in diagnosis, follow-up, and treatment evaluation.

COVID-19 can utilize angiotensin-converting enzyme2 (ACE2) as the cell receptor [22], so affect pulmonary interstitial pathology the parenchymal abnormalities resulting in $\mathrm{CT}$ changes that can be variable depending of the severity and stage of the disease [22-24].

\section{Springer Open}

๑ The Author(s). 2020 Open Access This article is licensed under a Creative Commons Attribution 4.0 International License, which permits use, sharing, adaptation, distribution and reproduction in any medium or format, as long as you give appropriate credit to the original author(s) and the source, provide a link to the Creative Commons licence, and indicate if changes were made. The images or other third party material in this article are included in the article's Creative Commons licence, unless indicated otherwise in a credit line to the material. If material is not included in the article's Creative Commons licence and your intended use is not permitted by statutory regulation or exceeds the permitted use, you will need to obtain permission directly from the copyright holder. To view a copy of this licence, visit http://creativecommons.org/licenses/by/4.0/. 
While peripheral posterior bilateral ground-glass opacities (GGO) with or without consolidation was the major hallmark of COVID-19, other variable CT findings were reported [25-31].

The aim of current work is to review the CT findings of COVID-19 in a pictorial study to help the radiologists to be familiar to imaging findings of COVID-19.

\section{Main text}

CT manifestations of COVID-19 (Figs. 1, 2, 3, 4, 5, 6, 7 and 8) Pulmonary findings

Ground-glass opacity GGO is defined as hazy lung areas of slightly increased attenuation without obscuring the bronchial and vascular margins; it can be caused by partial air displacement attributed to partial airspaces filling or interstitial thickening [32, 33]. It is considered the most common radiological abnormality seen in up to $98 \%$ in COVID-19 cases [9, 21-24].

In COVID-19, GGO is predominately peripheral and subpleural, either uni or bilateral [12-17]. In earlier study by Chung et al. [18], GGO was considered as earliest CT finding and detected in $57 \%$ of cases.

Consolidation Consolidation is defined as increase in the pulmonary parenchymal attenuation with obscuration of the vascular and airway wall margins due to pathological replacement of alveolar air by fluids, cells, or tissues. It can be multifocal, patchy, or segmental with subpleural location or along bronchovascular bundles $[32,33]$.

Literature shows consolidation prevalence to be about $2-64 \%$ in COVID-19 cases [11, 19, 20]. The pathology of consolidation of COVID-19 can be attributed to alveolar cellular fibromyxoid exudates [34]. Consolidation can occur as a progress of the disease or co-existed with GGO [20, 23].
Reticular pattern Reticular pattern refers to thickening of the pulmonary interstitial structures as interlobular septa and intralobular lines [32,33]; with linear opacities seen at CT studies, it can be explained by the interstitial lymphocyte infiltration [34]. Reticular pattern was noted in many COVID-19 CT studies, up to $70.6 \%$ of cases [1] which increases with prolonged course of the disease $[13,20]$.

Crazy-paving pattern The crazy-paving pattern is a linear pattern superimposed on a GGO background giving the appearance of irregular paving stones (crazy); it can be explained by alveolar edema and acute lung interstitial inflammation $[32,35]$. It was reported in $5-36 \%$ COVID-19 patients $[9,11]$. It can be a sign of disease progression $[9,24]$.

Air bronchogram Air bronchogram refers to the pattern of air-filled bronchi (dark) on the background of opacified alveoli (grey/white) [32] and was noted in previous studies of CT chest for COVID-19 [9, 13, 27]; however, the hypoattenuation of bronchi can be attributed to gelatinous mucus and not air [36]. Thus, some suggested to call it bronchiolectasis [9].

Bronchus deformation It is described as airway changes (bronchiectasis and thickening of bronchial wall thickening); it was reported in 10-20\% of COVID-19 patients $[1,9,11,15,22,26]$. It can be attributed to the inflammatory changes of bronchial wall leading to obstruction and subsequent destruction of bronchial wall with fibrosis and bronchiectasis change $[9,32]$.

Fibrosis Lung fibrosis was reported at CT studies of COVID-19 cases in previous series [12] in about $17 \%$ of cases. It can be explained by the replacement of cells by scar tissue in the healing process of chronic pulmonary inflammation; thus, it is considered to be a good

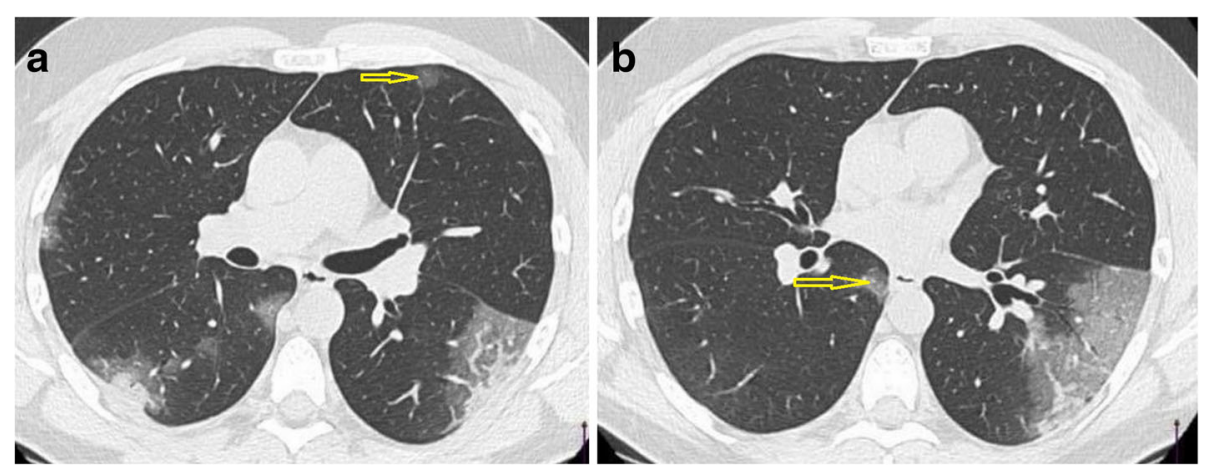

Fig. 1 CT chest axial cuts of COVID-19 patient. A: ground glass opacity (anterior segment of left upper lobe, yellow arrow) and combination of GGO and consolidation in both lower lobe (peripheral, subpleural). B: ground glass opacity (medial segment of right lower lobe, yellow arrow) as well as GGO and consolidation of left lower lobe (peripheral, subpleural) 

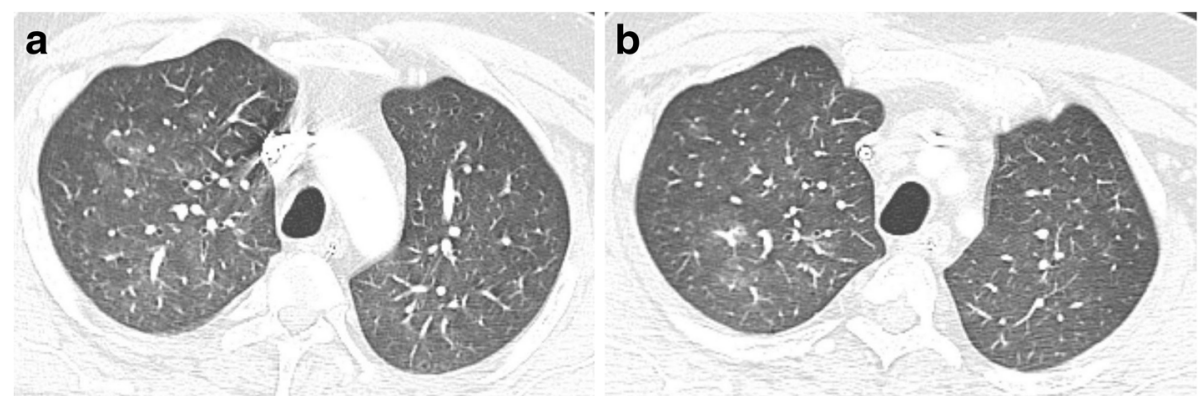

Fig. 2 a, b CT- chest of COVID-19 patient shows widespread faint ground glass opacity upper lung lobe as well as reticular shadowing bilaterally

prognosis by some author [12], while others claimed that it is of poor prognosis as it proceeds to interstitial pulmonary fibrosis disease $[28,35]$.

Pathological air containing spaces It is described as small air spaces within the lung; it can be due to pathological dilatation or air spaces or due to resorption of consolidation; some author described it as cavity [28], and other called it cystic changes [23] and cavity [32] or bubble sign [9].

Subpleural line It is described as thin $(1-3 \mathrm{~mm}$ thickness) curvilinear opacity that is parallel to the pleural surface and less than $1 \mathrm{~cm}$ deep to it [32]. It was described in about $20 \%$ of COVID-19 cases in some series and can be explained by pulmonary edema or fibrosis that takes place in COVD-19 $[11,20]$.

Vascular enlargement Pulmonary vessel dilatation, peri- and intralesional, was reported in some series [9]; however, it is assumed to be rare [25], while other reported it in $82.4 \%$ of cases [1]; it can be explained by

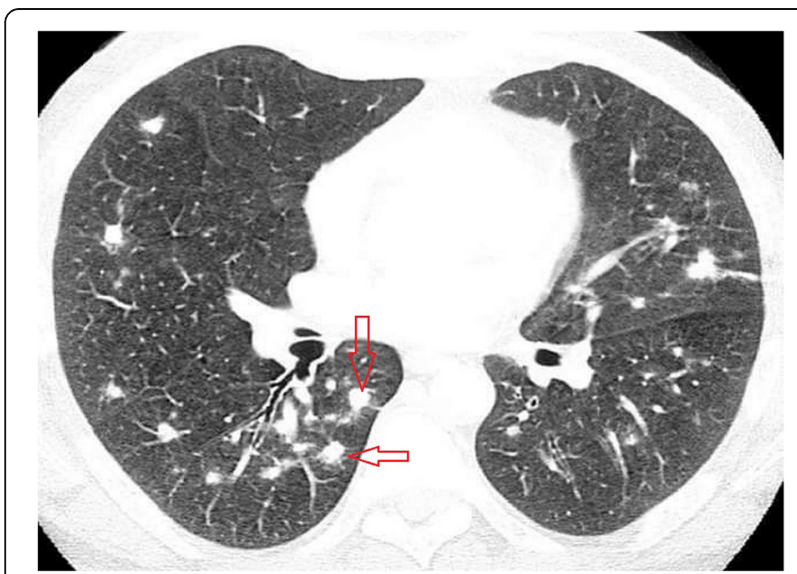

Fig. 3 CT scan shows multiple irregular nodules in right middle and lower lobe, lingula and anterior segment of left lower lobe with solid nodules surrounded by a ground glass (red arrow) capillary wall damage in response to inflammatory process-related factors [9].

Pulmonary nodules Nodule is described as a small (less than $3 \mathrm{~cm}$ ) round, oval, or irregular shaped well or poorly defined opacity in the lung [32]. It was reported in 3-13 of COVID-19 CT cases and mostly was multifocal irregular and can have halo sign $[1,9,12,31,37]$.

Halo sign and reversed halo sign Halo sign is described as ground-glass opacity surrounding a pulmonary nodule or mass and represents hemorrhage which was typically described in angioinvasive fungal infection or hypervascular deposits and was attributed to perifocal hemorrhage [31, 32, 38]. In COVID-19, it was described in some report to be about $17.6 \%$ but pathology is not understood yet $[1,31]$. On the other hand, reversed halo sign (atoll sign) is described as a central ground-glass opacity with denser surrounding crescentic or ring

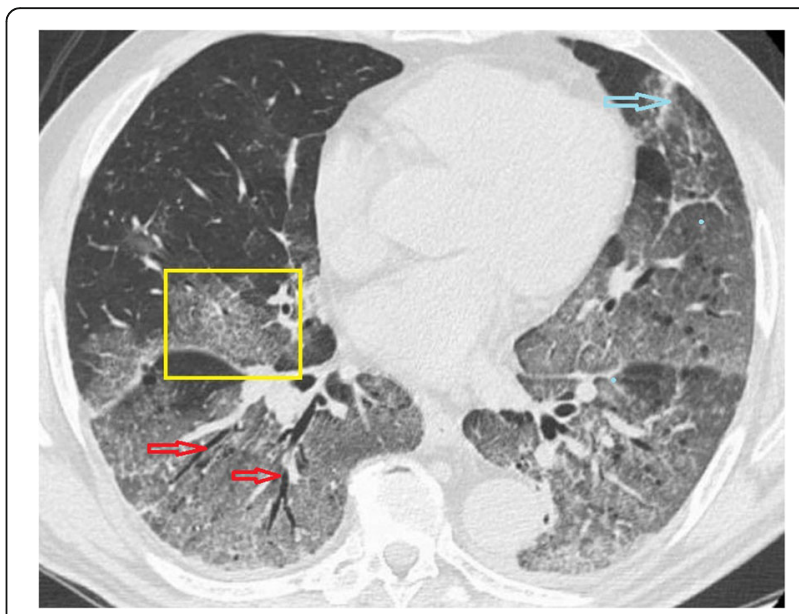

Fig. 4 CT scan of COVID-19 patient shows reticular pattern superimposed on the background of GGO with crazy paving stones signs at anterior segment of right lower lobe (yellow box), bronchiolar dilatation (red arrows) at right lower lobe, fibrotic changes (blue arrow) are also noted 


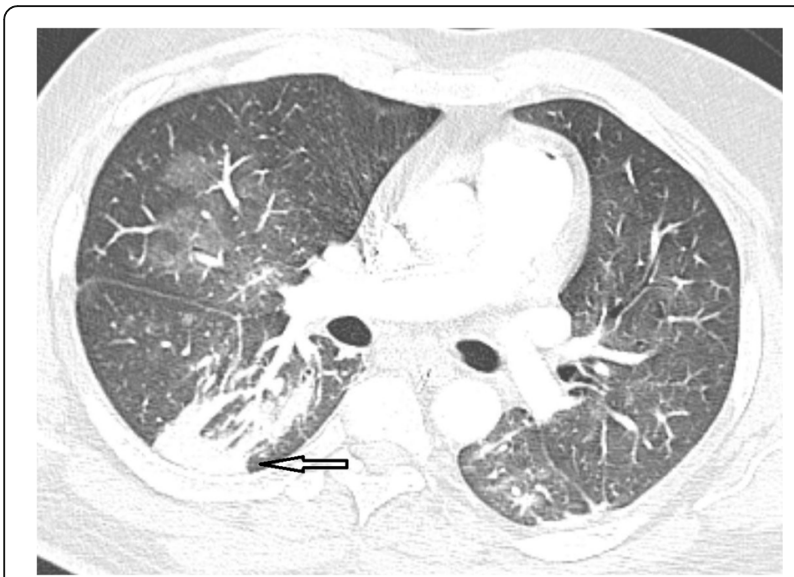

Fig. 5 CT scan of COVID-19 patient shows Multiple areas of GGO as well as reticular pattern at anterior segment of upper lobes as well as superior segments of lower lobes

consolidation [32]; it was noted in COVID-19 cases in $3.9 \%$ of cases [1] and explained by the progression of disease so that consolidation surrounds GGO or lesion regression with its center being of low attenuation $[9$, $19,27,39]$.

\section{Extrapulmonary findings}

Pleural changes Pleural thickening was reported in COVID-19 with higher incidence than effusion [23] with prevalence of up to $32 \%$ of COVID-19 cases in some series [19, 23], while pleural effusion was reported as a rare finding in COVID-19 cases with incidence of $2 \%$ and may be a bad prognostic sign [11, 23]; furthermore, some suggested that occurrence or pleural effusion and

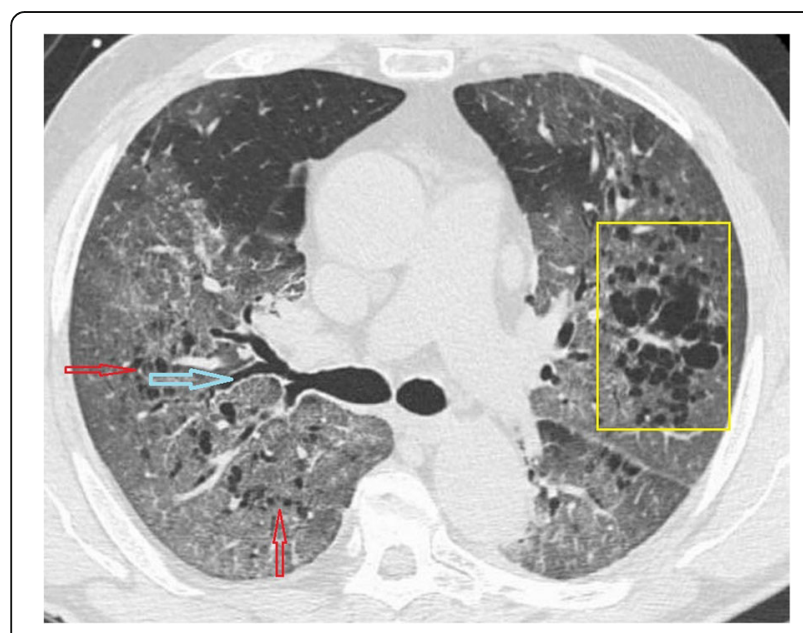

Fig. 6 CT scan of COVID-19 patient shows reticular pattern superimposed on the background of GGO with air trapping at lower lobes (red arrow) as well as cystic changes at left lower lobe (yellow box). Bronchiolar irregularity at right lower lobe (blue arrow)

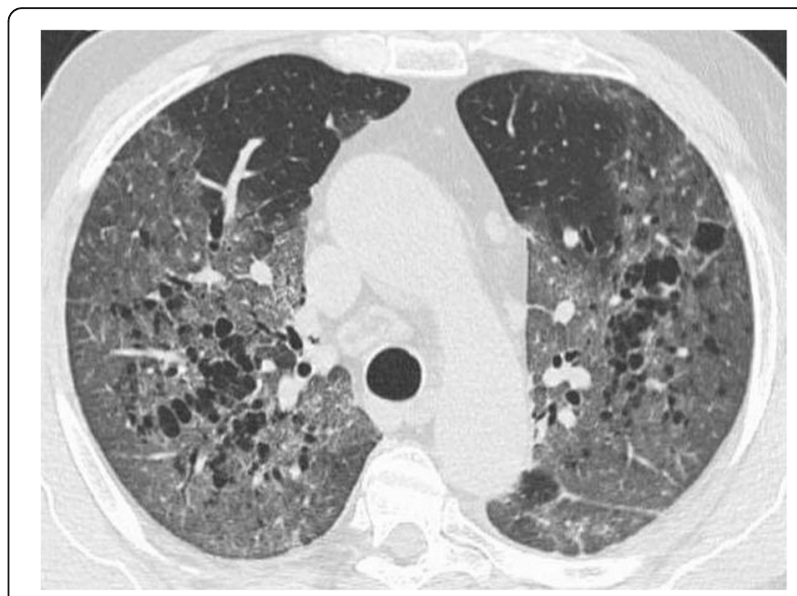

Fig. 7 CT scan of COVID-19 patient shows reticular pattern superimposed on the background of GGO with nodular shadows and bilateral small cystic changes at upper lobes

extensive tiny pulmonary nodules to be due to bacterial superinfection [29].

Mediastinal lymphadenopathy It describes enlarged lymph nodes ( $>1 \mathrm{~cm}$ short axis) [32] which may be assign of severe COVID-19 infection; it was reported in 0$8 \%$ of COVID-19 cases [1, 20, 23].

Pericardial effusion Pericardial effusion was earlier reported as being rare $(<5 \%)$ finding in COVID-19 cases and can be explained by the severe inflammatory process; some reports described it with a higher incidence in critical COVID-19 cases than milder cases [11].

So, the CT findings in COVID-19 are variable. While mild cases can show bilateral ground-glass opacities and small areas of subsegmental consolidation with the advance of the disease, there can be bilateral multiple

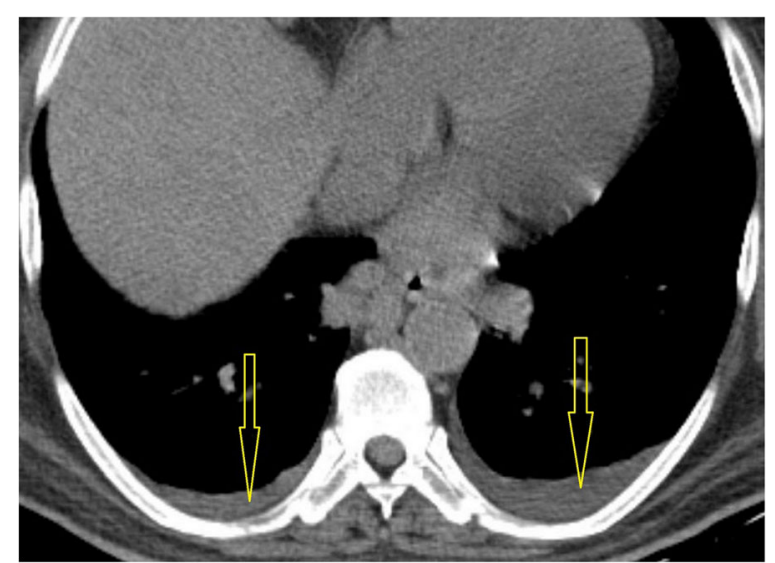

Fig. 8 CT scan of COVID-19 patient shows minimal bilateral pleural effusion (yellow arrows) 
subsegmental and lobular consolidation. In advanced cases, CT can reveal heterogeneous widespread bilateral with air bronchogram and bronchial deformation as well as septal thickening and crazy-paving appearance.

\section{Conclusion}

Isolation of COVID-19 patients is of critical importance to control its spread; thus, early identification of cases is vital. While GGO and consolidation are on top of COVID-19 CT chest findings, the radiologist should be familiar with other possible findings. Further future studies with pathological correlation will help for more understanding of the imaging findings and its value in assessing of prognosis.

\section{Abbreviations}

ACE2: Angiotensin-converting enzyme-2; COVID-19: Coronavirus disease 2019; CRP: C-reactive protein; CT: Computed tomography; GGO: Ground-glass opacities; RBC: Red blood cells; RT-PCR: Real-time reverse transcription polymerase chain reaction; WBC: White blood cells; WHO: World Health Organization

\section{Acknowledgements}

Not applicable

\section{Authors' contributions}

AT: conceived of the study, participated in its design and coordination, drafted the manuscript, and carried out radiological results. AM: participated in study design and helped in drafting the manuscript and radiological results. EM: participated in study design and helped in drafting the manuscript and radiological results. All authors read and approved the final manuscript.

\section{Funding}

Not applicable.

\section{Availability of data and materials}

The data that support the findings of this study are available on request from the corresponding author.

\section{Ethics approval and consent to participate}

This study was approved from ethical committee of the institution in February 2020 as well as informed written consent from the patients included in this study was taken.

\section{Consent for publication}

All authors read and approved the final manuscript.

All patients included in this research gave written informed consent to publish the data contained within this study.

\section{Competing interests}

The authors declare that they have no competing interests.

\section{Author details}

'Department of Radiodiagnosis, Faculty of Medicine, Zagazig University, PO. BOX 184, Sharkia, Zagazig 44511, Egypt. ${ }^{2}$ Department of Radiodiagnosis, Faculty of Medicine, Al-Azhar University, Cairo, Egypt.

Received: 6 April 2020 Accepted: 26 June 2020

Published online: 07 July 2020

\section{References}

1. Li Y, Xia L (2020) Coronavirus disease 2019 (COVID-19): role of chest CT in diagnosis and management. AJR 214:1-7

2. Chen N, Zhou M, Dong X et al (2020) Epidemiological and clinical characteristics of 99 cases of 2019 novel coronavirus pneumonia in Wuhan, China: a descriptive study. Lancet 395:507-513
3. World Health Organization (2020) Coronavirus disease 2019 (COVID-19) situation report-42. World Health Organization, Geneva. Available via https:/www.who.int/docs/default-source/coronaviruse/20200302-sitrep-42covid-19.pdf?sfvrsn=d863e045 2. Accessed 3 Mar 2020

4. World Health Organization (2020) Coronavirus disease 2019 (COVID-19) situation report-39. World Health Organization, Geneva. Available via https://www.who.int/docs/default-source/ coronaviruse/situation-reports/2 0200228-sitrep-39-covid-19.pdf? sfursn=5bbf3e7d_2. Accessed 3 Mar 2020

5. Guan WJ, Ni ZY, Hu Y et al (2020) Clinical characteristics of coronavirus disease 2019 in China. N Engl J Med

6. Zhu N, Zhang D, Wang W et al (2020) A novel coronavirus from patients with pneumonia in China, 2019. N Engl j med 382(8):727-733

7. Fang Y, Zhang H, Xie J et al (2020) Sensitivity of chest CT for COVID-19: comparison to RT-PCR. Radiology

8. Qian L, Yu J, Shi H. Severe acute respiratory disease in a Huanan seafood market worker: images of an early casualty. Radiology 2020: Cardiothoracic Imaging.

9. Ye Z, Zhang Y, Wang Y, Huang Z, et al. .Chest CT manifestations of new coronavirus disease 2019 (COVID-19): a pictorial review. European Radiology 2020.

10. Wang D, Hu B, Hu C, et al. Clinical characteristics of 138 hospitalized patients with 2019 novel coronavirus-infected pneumonia in Wuhan, China. JAMA 2020.

11. Kunhua Li JW, Wu F et al (2020) The clinical and chest CT features associated with severe and critical COVID-19 pneumonia. Invest Radiol

12. Pan $Y$, Guan $H$, Zhou S, et al. Initial CT findings and temporal changes in patients with the novel coronavirus pneumonia (2019- nCoV): a study of 63 patients inWuhan, China. Eur Radiol 2020.

13. Song F, Shi N, Shan F et al (2020) Emerging coronavirus 2019-nCoV pneumonia. Radiology

14. Ng M-Y, Lee EY, Yang J, et al. Imaging profile of the COVID-19 infection: radiologic findings and literature review. Radiology: Cardiothoracic Imaging 2020.

15. Kanne JP. Chest CT findings in 2019 novel coronavirus (2019-nCoV) infections from Wuhan, China: key points for the radiologist. Radiology 2020.

16. Lee KS. Pneumonia associated with 2019 novel coronavirus: can computed tomographic findings help predict the prognosis of the disease? Korean J Radiol 2020.

17. Kim H. Outbreak of novel coronavirus (COVID-19): what is the role of radiologists? Eur Radiol 2020.

18. Chung M, Bernheim A, Mei X et al (2020) CT imaging features of 2019 novel coronavirus (2019-nCoV). Radiology

19. Bernheim A, Mei X, Huang M et al (2020) Chest $C T$ findings in coronavirus disease-19 (COVID-19): relationship to duration of infection. Radiology

20. Wu J,Wu X, Zeng W, et al. Chest $C T$ findings in patients with corona virus disease 2019 and its relationship with clinical features. Invest Radiol 2020.

21. National Health Commission of the People's Republic of China (2020) The diagnostic and treatment protocol of COVID-19. China. Available via http:// www.gov.cn/zhengce/zhengceku/2020- 02/19/content_5480948.htm Accessed 3 Mar 2020.

22. Xu X, Chen P, Wang J et al (2020) Evolution of the novel coronavirus from the ongoing Wuhan outbreak and modeling of its spike protein for risk of human transmission. Sci China Life Sci:1-4

23. Shi $\mathrm{H}$, Han $\mathrm{X}$, Jiang $\mathrm{N}$, et al. Radiological findings from 81 patients with COVID-19 pneumonia in Wuhan, China: a descriptive study. Lancet Infect Dis. 2020.

24. Pan F, Ye T, Sun P, et al. Time course of lung changes on chest $C T$ during recovery from 2019 novel coronavirus (COVID- 19) pneumonia. Radiology 2020.

25. Xie X, Zhong Z, Zhao W et al (2020) Chest CT for typical 2019-nCoV pneumonia: relationship to negative RTPCR testing. Radiology

26. Fang Y, Zhang H, Xu Y et al (2020) CT manifestations of two cases of 2019 novel coronavirus (2019-nCoV) pneumonia. Radiology

27. Yoon S, Lee K, Kim J et al. Chest radiographic and CT findings of the 2019 novel coronavirus disease (COVID-19): analysis of nine patients treated in Korea. Korean J Radiol 2020.

28. Kong W, Agarwal PP. Chest imaging appearance of COVID- 19 infection. Radiology: Cardiothoracic Imaging 2020.

29. Kanne JP, Little BP, Chung JH, et al. Essentials for radiologists on COVID-19: an update-radiology scientific expert panel. Radiology 2020. 
30. Kay F, Abbara S. The many faces of COVID-19: spectrum of imaging manifestations. Radiology: Cardiothoracic Imaging 2020.

31. Li X, Zeng X, Liu B, et al. COVID-19 infection presenting with CT halo sign. Radiology: Cardiothoracic Imaging 2020

32. Hansell DM, Bankier AA et al (2008) Fleischner Society: glossary of terms for thoracic imaging. Radiology 246:697-722

33. Ajlan AM, Ahyad RA, Jamjoom LG et al (2014) Middle East respiratory syndrome coronavirus (MERSCOV) infection: chest CT findings. AJR Am J Roentgenol 203:782-787

34. Xu Z, Shi L, Wang Y et al (2020) Pathological findings of COVID-19 associated with acute respiratory distress syndrome. Lancet Respir Med

35. Wong K, Antonio GE, Hui DS et al (2003) Thin-section CT of severe acute respiratory syndrome: evaluation of 73 patients exposed to or with the disease. Radiology 228:395-400

36. Xi Liu RW, Guogiang Q, Wang Y et al (2020) A observational autopsy report of COVID-19 (Chinese). J Forensic Med 36:19-21

37. Ai T, Yang Z, Hou H et al (2020) Correlation of chest CT and RTPCR testing in coronavirus disease 2019 (COVID-19) in China: a report of 1014 cases. Radiology

38. Kuhlman JE, Fishman EK, Siegelman S (1985) Invasive pulmonary aspergillosis in acute leukemia: characteristic findings on $C T$, the $C T$ halo sign, and the role of $C T$ in early diagnosis. Radiology 157:611-614

39. Xu RDM, Li L, Zhen Z, et al. CT imaging of one extended family cluster of corona virus disease 2019 (COVID-19) including adolescent patients and "silent infection". Quant Imaging Med Surg. 2020.

\section{Publisher's Note}

Springer Nature remains neutral with regard to jurisdictional claims in published maps and institutional affiliations.

\section{Submit your manuscript to a SpringerOpen ${ }^{\circ}$ journal and benefit from:}

- Convenient online submission

- Rigorous peer review

- Open access: articles freely available online

- High visibility within the field

- Retaining the copyright to your article 